\title{
ТЕОРЕТИЧЕСКИЕ АСПЕКТЫ СТРАТЕГИЧЕСКОГО ПЛАНИРОВАНИЯ
}

\author{
(c) 2021 Чмышенко Елена Георгиевна \\ доктор экономических наук, профессор \\ Оренбургский государственный университет, Россия, Оренбург \\ E-mail: elenach2@yandex.ru \\ (c) 2021 Чмышенко Екатерина Владимировна \\ кандидат экономических наук, доцент \\ Оренбургский государственный университет, Россия, Оренбург \\ E-mail: minerva75@mail.ru
}

В статье сделан вывод об отсутствии единства в научном сообществе при рассмотрении понятия «стратегическое планирование», в связи чем предложено авторское видение данного понятия с позиций функционального и процессного подходов. На основе исследования стратегических документов выявлены недостатки в системе стратегического планирования в стране и регионах по формированию субъектов и объектов планирования. Обозначены проблемы организации стратегического планирования в регионах. В статье представлены основные элементы процессного подхода к стратегическому планированию и его этапы.

Ключевые слова. Законы РФ, стратегическое планирование, система, субъект, объект, организационная структура, процесс планирования.

Переход России от централизованной к рыночной экономике предопределил серьёзные изменения в государственном управлении страной, в первую очередь, это относится к организации стратегического планирования. В России за последние десятилетия накоплен определённый теоретический и практический опыт стратегического планирования. Правительством РФ приняты два федеральных закона от 20 июля 1995 года № 115-ФЗ «О государственном прогнозировании и программах социально-экономического развития Российской Федерации» и 28 июня 2014 года № 172 -Ф3 «О стратегическом планировании в Российской Федерации».

Первые российские научные исследования в области стратегического планирования представлены в трудах В.П.Бауэра, А.В.Бузгалина, О.Б.Бухвальда, А.Г.Гранберга, Б.М.Гринчель, С.Ф.Жилкина, Б.С Жихаревича, Г.Б.Клейнер, А.И.ККолганова, О.В.Коломийченко, Ю.Н.Лапыгина, В.Н.Лексина, К.С.Львова, П.А.Минакира, В.М.Полтеровича, В.Е.Селивёрстова, О.О.Смирновой, Л.С.Шеховцевой, А.Н.Швецова, И.Е. Рисина, В.Е. Рохчина и других ученых.

Однако в имеющихся работах и публикациях не решены многие теоретико-методологические и методические вопросы. В настоящее время российской наукой еще не создана единая об- щепризнанная методология стратегического планирования и, в основном используются теоретические наработки западных учёных, адаптированные к российской действительности. Следует отметить, что западная теория стратегического планирования в большей степени разработана не на государственном уровне, а на уровне коммерческих структур.

Поэтому сегодня существует потребность в создании теории стратегического планирования не только по отношению к коммерческим структурам, но и к другим уровням планирования: мегаэкономическому, макроэкономическому (федерация), мезоэкономическому (регион, муниципалитет), отраслевому и микроэкономическому, что особенно актуально для России.

Необходимость развития методологии стратегического планирования заключается в том, что она заметно отличается от других теорий планирования: в частности, понятийным аппаратом, принципами, технологией, методами, механизмами, процедурами и др. Кроме того, без наличия хорошей теоретической базы невозможно решать прикладные вопросы.

Основой любой методологии выступает понятийный аппарат, значимость которого заключается в том, что он позволяет единообразно понимать взаимосвязи и процессы и соответственно принимать наиболее правильные реше- 
ния. В настоящее время в научной литературе нет единства в определении таких важных понятий, как стратегическое планирование, стратегия, стратегический план. Разные подходы к данным понятиям приводят к искажению их смыслового значения и неоднозначному применению [9].

Определение понятия стратегическое планирование» как в зарубежной, так и российской научной литературе достаточно много. Например, под стратегическим планированием И.Ансофф понимает «логический, аналитический процесс определения будущего положения фирмы в зависимости от внешних условий... » [1]; У.Кинг и Д.Клиланд - «процесс определения целей организации и их изменений, ресурсов, необходимых для их достижения...» [3]; М. Мескон считает, что это «набор действий и решений, предпринятый руководством, который ведёт к разработке специфических стратегий, предназначенных для того, чтобы помочь организации достичь своих целей» [5]; Е.П.Голубков считает, что это «процесс разработки и поддержания стратегического равновесия между целями и возможностями организации...» [2]; А.Н.Швецов, А.Н.Демьяненко и В.Н.Украинский - определяют как «инструмент современного экономического развития...» [10], П.В Магданов понятие «стратегическое планирование» рассматривает как «систему знаний, относящихся к процессам определения будущего и планирования развития какого-либо экономического субъекта» [4].

Определение стратегического планирования представлено в Федеральном законе РФ № 172ФЗ как «деятельность участников по целеполаганию, прогнозированию, планированию и программированию...» [8]. Некорректность данного определения очевидна:

1) под планированием понимается планирование;

2) целеполагание - один из этапов планирования;

3) прогнозирование инструмент стратегического планирования;

4) программирование - промежуточный элемент плана, может выступать как предплановое решение, так и конкретизировать отдельный аспект плана.

Представленные примеры ярко иллюстрируют большое разнообразие в определении понятия «стратегическое планирование», что требует уточнения данной категории.
Предлагаем подойти к определению понятия «стратегическое планирование» с позиций двух подходов: функционального и процессного. Считаем, что, в первую очередь, необходимо исходить из понимания планирования, в том числе стратегического, как основной функции управления, то есть определенного вида деятельности. Исходя из этого дадим авторское определение: «Стратегическое планирование представляет собой деятельность субъекта планирования, направленную на объект с целью конструирования будущего и способов его достижения, исходя из особенностей объекта, современных реалий и тенденций внешней среды». Из определения видно, что ключевыми элементами выступают: субъект, объект, цель, особенности объекта и внешняя среда, формирование которых составляет основу стратегического планирования.

Остановимся на положениях, позволяющих дополнить и представить позицию авторов по основным элементам стратегического планирования, а более подробно - на субъекте и объекте планирования.

Считаем, что субъектом государственного стратегического планирования должен выступать институциональный орган, осуществляющий планирование. Сегодня в стране отсутствует единый субъект планирования. Отказ от центрального органа планирования произошел в 1990-х годах XX века, когда был упразднен Госплан СССР.

В настоящее время на законодательном уровне не определено понятие «субъект планирования». Так, в Федеральном законе № 172Ф3 «О Стратегическом планировании» вместо понятия «субъекты планирования» в ст. 9 указаны участники планирования: Президент Российской Федерации; Федеральное собрание РФ; Правительство РФ; Совет безопасности РФ; Счетная палата РФ; Центральный банк РФ; федеральные органы исполнительной власти [8]. На уровне субъектов Российской Федерации к участникам планирования отнесены: законодательный орган субъекта РФ; высшее должностное лицо субъекта РФ; высший исполнительный орган субъекта РФ; исполнительные органы государственной власти субъекта; контрольносчётный орган субъекта.

Участники планирования не являются субъектами планирования. Так как их основными функциям выступают согласование, координирование и утверждение планов, в то время как 
функция субъекта - это непосредственное планирование.

В качестве субъектов планирования на федеральном уровне в Министерстве экономического развития было сформировано два департамента:

1 Департамент макроэкономического анализа и прогнозирования.

2 Департамент бюджетного планирования и государственных программ.

Основными задачами данных структур выступают разработка и реализация стратегий развития страны. С их созданием с 2000 года начался процесс формирования стратегических документов: в 2000 году создана «Стратегия социально-экономического развития Российской Федерации до 2010 года»; в 2008 - «Концепция долгосрочного социально-экономического развития Российской Федерации на период до 2020 года»; в 2015 г. - «Стратегия национальной безопасности»; в 2016 г.- «Стратегия научнотехнологического развития РФ до 2035 года»; в 2017г.-«Стратегияэкономическойбезопасности до 2030 года»; в 2019 г.- «Стратегия пространственного развития РФ на период до 2025 года».

Кроме того, департаментами Минэкономразвития РФ проведена большая работа по разработке стратегий для важнейших отраслей национального хозяйства, а на региональном уровне практически во всех 85 регионах России разработаны «Стратегии социально-экономического развития на период до 2030 года».

Несмотря на проведенную большую работу в области стратегического планирования со стороны государственных органов, она не привела к качественным изменениям в экономических процессах России. Остаются низкими темпы роста ВВП, который в последние годы увеличивается за счет добычи и экспорта энергоносителей. Продолжается ухудшение структуры промышленного производства, уменьшается доля отраслей с высокой добавленной стоимостью.

Разработанные на федеральном уровне стратегические документы, на которые истрачены миллиарды рублей, не дают ответа на многие вопросы. В большинстве своем они представляют собой механический набор «правильных задач», «добрых пожеланий», абстрактных рекомендаций и по своей сути прогнозируют воспроизведение сырьевой направленности России. Отсутствие единого целостного стратегического документа и обилие различных разрозненных ведомственных и отраслевых стратегий, и программ, зачастую вступающих между собой в противоречие - одна из основных причин неэффективности системы стратегического государственного планирования экономики в России.

Таким образом, создание огромного количества стратегических документов разного уровня не перешло в реальный инструмент эффективного управления и одной из причин является, по мнению российских ученых, отсутствие специального органа государственного планирования.

Многие ученые считают, что на федеральном уровне должен быть создан специальный орган по планированию. Еще в 2011 году на научном семинаре по проблемам стратегического государственного планирования и управления в современной России член-корреспондент РАН Б.Г.Клейнер обосновывал целесообразность создания государственной организации, осуществляющей руководство процессом стратегического планирования в стране - Росплана [6].

Вопрос о создании специализированного органа по планированию широко обсуждался и на круглом столе, проведенном фракцией политической партии Справедливая Россия и фонда развития инновационного предпринимательства Торгово-промышленной палаты РФ в 2017 году. Так, выступающие М.В.Емельянов, К.Н.Андрианов и др. отмечали, что для развития национальной экономики необходимо создать Федеральный Комитет по стратегическому планированию. Одной из основных задач Комитета должны стать оптимизация и интеграция ныне разрозненного множества федеральных, отраслевых и региональных стратегий, и разработка единого стратегического документа социально-экономического развития Российской Федерации - Генерального (5-6-летнего) индикативного) плана [7].

Считаем, что главными функциями данного органа должны стать:

- организация единой системы стратегического планирования;

- определение необходимых ресурсов для достижения целей и задач;

- нормативно-правовое, научно-техническое, информационное и кадровое обеспечение;

- обеспечение согласованности и иерархической взаимоувязки стратегических планов (страны, региона, отрасли, муниципалитета и бизнеса); 
- осуществление стратегического контроля.

Мировой опыт свидетельствует, что в большинстве ведущих индустриально-развитых странах, в структуре правительств функционируют соответствующие специальные плановые органы. Так, во Франции существует Генеральный комиссариат по планированию, в КНР - Государственный плановый комитет, в Индии Плановая комиссия Индии и другие. Эти органы обеспечивают целостность системы государственного регулирования рыночной системы хозяйствования. Опыт ведущих зарубежных стран и отечественных корпораций свидетельствует о необходимости существования специального органа по планированию.

Отметим, что и на уровне субъектов РФ также до сих пор нет четкого понимания субъектов стратегического планирования. Например, в ряде областей вообще отсутствуют структуры, занимающиеся стратегическим планированием (Оренбургская, Рязанская, Калужская области, Пермский край и др.). Регионам приходится заказывать разработку стратегических документов различным организациям.

В настоящее время в стране сформировалось множество организаций, предлагающих свои услуги по разработке стратегических планов (Институт социально-экономических и политических исследований, Центры стратегических разработок, Ресурсный центр по стратегическому планированию, ежегодный форум лидеров стратегического планирования, различные консалтинговые фирмы, а также большое количество так называемых бизнес-аналитиков).

Подготовка стратегических документов требует специальных знаний в области стратегического планирования, практического опыта исполнителей. А поскольку возникло много коммерческих структур, то поиск профессиональных исполнителей в настоящее время является большой проблемой.

Ряд субъектов РФ хотя и имеет в составе правительства организационные структуры по стратегическому планированию, однако и для этих регионов проблема профессионалов в области стратегического планирования стоит остро, учитывая то, что до сих пор существует недостаток методических рекомендаций по организации регионального стратегического планирования. Например, нет четкого понятия организационной структуры субъектов, выполняющих функции стратегического планирования.
Так, подразделения по стратегическому планированию могут находиться в составе министерств (Самарская, Новосибирская, Свердловская, Нижегородская и др. области), либо комитетов (Волгоградская область), либо департаментов (Белгородская, Ярославская области) (таблица 1).

Данные таблицы 1 свидетельствуют, что подразделения по стратегическому планированию имеют разные названия структур и количество подразделений (от 1 до 3). Статус подразделения и его название играют важную роль, так как они определяют иерархию целей, выполняемые задачи, функции и численность исполнителей. Например, если сектор - это небольшая организационная единица входящая в состав отдела в Нижегородской области правильнее было бы сформировать отдел стратегического планирования с двумя секторами: проектного управления и программного проектирования.

Следующий важный элемент стратегического планирования - объект. В научной литературе и на практике до сих пор нет четкого понимания объектов стратегического планирования. Это прослеживается в документах как на федеральном, так и региональном уровнях. Авторами был проведен выборочный анализ стратегических планов субъектов РФ, который выявил недостатки в определении объектов планирования. Так, многие обозначенные объекты в планах просто ими не являются, а относятся либо к целям, либо направлениям, либо к механизмам реализации плана.

Например, в качестве объектов в стратегических планах регионов РФ выступают внешнеэкономическая деятельность, человеческий потенциал, демографическая политика, инвестиционная политика, правопорядок (Свердловская область), инновационная система, экономические зоны, социально-экономическая политика (Мурманская область), социальная политика, молодежная политика, инновационный комплекс, креативные индустрии, финансовый сектор (Оренбургская область), демографическая, молодежная и семейная политика, социокультурный потенциал, промышленная, инновационная, научно-техническая, агропромышленная политика, конкурентная среда (Пермская область) [9].

Как видно из примеров, часто встречаются в качестве объектов различная политика. Политика не может выступать объектом, так как 
Таблица 1. Примеры подразделений по стратегическому планированию в структуре исполнительной власти отдельных субъектов РФ

\begin{tabular}{|c|c|c|}
\hline Субъект РФ & $\begin{array}{c}\text { Структура исполни- } \\
\text { тельной власти }\end{array}$ & Подразделение по стратегическому планированию \\
\hline $\begin{array}{l}\text { Самарская } \\
\text { область }\end{array}$ & $\begin{array}{l}\text { Министерство эконо- } \\
\text { мического развития, } \\
\text { инвестиций и торговли }\end{array}$ & $\begin{array}{l}\text { Департамент прогнозирования и стратегического планиро- } \\
\text { вания: } \\
\text { - управление сводного программно-целевого планирования и } \\
\text { прогнозирования финансовых ресурсов региона; } \\
\text { - управление сводного прогнозирования и стратегического пла- } \\
\text { нирования развития региона }\end{array}$ \\
\hline $\begin{array}{l}\text { Нижегородская } \\
\text { область }\end{array}$ & $\begin{array}{l}\text { Министерство эконо- } \\
\text { мического развития и } \\
\text { инвестиций }\end{array}$ & $\begin{array}{l}\text { Управление перспективного и проектного управления: } \\
\text { - отдел проектного управления; } \\
\text { - сектор стратегического планирования; } \\
\text { - сектор программного планирования }\end{array}$ \\
\hline $\begin{array}{l}\text { Свердловская } \\
\text { область }\end{array}$ & $\begin{array}{l}\text { Министерство эконо- } \\
\text { мики и территориаль- } \\
\text { ного развития }\end{array}$ & $\begin{array}{l}\text { Департамент стратегического и территориального разви- } \\
\text { тия: } \\
\text { - отдел методического обеспечения и координации стратегиче- } \\
\text { ского планирования; } \\
\text { - отдел стратегического развития территорий }\end{array}$ \\
\hline $\begin{array}{l}\text { Новосибирская } \\
\text { область }\end{array}$ & $\begin{array}{l}\text { Министерство эконо- } \\
\text { мического развития }\end{array}$ & $\begin{array}{l}\text { Управление анализа и сводного планирования социально- } \\
\text { экономического развития региона: } \\
\text { - отдел отраслевого планирования, программ развития соци- } \\
\text { альной сферы и инфраструктуры; } \\
\text { - отдел анализа, организации и совершенствования планиро- } \\
\text { вания }\end{array}$ \\
\hline $\begin{array}{l}\text { Ярославская } \\
\text { область }\end{array}$ & $\begin{array}{l}\text { Департамент экономи- } \\
\text { ки и стратегического } \\
\text { планирования }\end{array}$ & $\begin{array}{l}\text { Oтдел планирования и мониторинга территории развития; } \\
\text { Отдел государственных программ; } \\
\text { Отдел организации проектной деятельности }\end{array}$ \\
\hline $\begin{array}{l}\text { Волгоградская } \\
\text { область }\end{array}$ & $\begin{array}{l}\text { Комитет экономи- } \\
\text { ческой политики и } \\
\text { развития }\end{array}$ & Отдел планирования и мониторинга \\
\hline
\end{tabular}

по определению - это совокупность мер, действия правительства по выбору и осуществлению управленческих решений по отношению к объекту.

Считаем, что на региональном уровне в качестве объектов стратегического планирования могут выступать муниципальные образования, кластеры, территориально-производственные комплексы, крупные корпорации, отрасли и виды деятельности, рынки (национальный, региональный, локальный).

Далее обозначим авторское видение стратегического планирования с позиций процессного подхода. Для этого считаем необходимым рассмотреть его, как:

- процесс организации планирования;

- процесс последовательного выполнения взаимосвязанных видов деятельности.

1. Процесс организации стратегического планирования заключается в определенных действиях:

- назначение владельца процесса;

- регламентирование процесса (определение входа, выхода, клиентов, поставщиков, процедур, стандартов, правил, норм, методов, спо- собов, приёмов, средств);

- описание смежных процессов и подфункций в каждом процессе;

- определение участников процесса;

- определение ответственности каждого исполнителя.

2. Процесс стратегического планирования как последовательность взаимосвязанных видов деятельности заключается в создании многоуровневой и многостадийной государственных систем планирования.

В научной литературе пока нет общего мнения по формированию стадий стратегического планирования, как на федеральном, так и региональном уровнях. За основу берутся шаблоны стратегического планирования, разработанные для предприятий и корпораций. Однако использование этих шаблонов к стране и регионам неприемлемо, так как они не учитывают специфических особенностей данных объектов.

Отсутствие методических рекомендаций по процессу стратегического планирования приводит к созданию документов низкого качества. О том, что в этом вопросе существует много проблем, свидетельствует проведенный авторами 
анализ структуры стратегических планов отдельных регионов РФ. Было выявлено, что они различаются по количеству разделов (от 5 до 12), содержанию и наполнению. Во многих планах нарушена логика процесса стратегического планирования и практически отсутствуют разработанные стратегии.

Если теорией и практикой признано, что процесс стратегического планирования необходимо начинать с видения, миссии и системы целей, то например, в Кировской и Оренбургской областях начали сразу с разработки стратегии, в Нижегородской области видение не в начале, а в конце процесса, а тип стратегии обозначен только в плане Самарской области.

Обобщив научные труды российских ученых и практику стратегического планирования, представим свое видение процесса регионального стратегического планирования. На наш взгляд, он должен состоять из семи укрупненных этапов:

1) определение позиций региона в общественном разделении труда;

2) формирование объектов стратегического планирования;

3) стратегический анализ внешней и внутренней среды для каждого объекта планирования;
4) формирование системы целей для каждого объекта;

5) разработка стратегий для каждой цели;

6) выбор альтернативных стратегий и их оценка;

7) реализация стратегий (разработка стратегического плана, целевых программ, инвестиционных проектов);

8) контроль и анализ выполнения стратегий.

Таким образом, проведенные исследования позволили авторам сделать вывод о множестве еще не решенных проблем в практике стратегического планирования. К ним можно отнести: слабые теоретические и методологические разработки в области стратегического планирования; отсутствие централизованного органа планирования; недостаток знаний, компетентности, опыта исполнителей; формальный подход к организации стратегического планирования; низкое качество стратегических документов; слабая практическая реализация стратегических планов.

В России предстоит еще большая работа по становлению стратегического планирования и процесс создания целостной системы эффективного стратегического планирования ещё далёк от своего завершения.

\section{Библиографический список}

1. Ansoff, N. L. The State of Practice in Planning systems / N. L. Ansoff // Sloan Management Review. - 1977.-S. 1-24.

2. Голубков, Е. П. Стратегическое планирование и роль маркетинга в организации. / Е. П. Голубков // Маркетинг в России и за рубежом.-2012.- № 3.- С.14-17.

3. Кинг, У. Стратегическое планирование и хозяйственная политика / У. Кинг, Д. Клиланд. - Пер. с англ.- М.: Прогресс, 1982.- 399 с.

4. Магданов, П.В.Процесс стратегического планирования в корпорации [Электронный ресурс] / П. В. Магданов // Вестник Пермского университета, 2012._- Вып. 1(12). - URL: https://cyberleninka.ru/article/n/protsessstrategicheskogo-planirovaniya-v-korporatsii/viewer (дата обращения: 02.12.2020).

5. Мескон, М. Основы менеджмента / М. Мескон, М. Альберт, Ф. Хедоури.- М.: Дело, 1999. - 800 с.

6. Проблемы стратегического государственного планирования и управления в современной России: Материалы научного семинара, вып. 5 (43).- М.: Научный эксперт, 2011._- 96 с.

7. Развитие системы стратегического планирования в Российской Федерации: Материалы «круглого стола» фракции Политической партии Справедливая Россия и фонда развития инновационного предпринимательства Торгово-промышленной палаты Российской Федерации.- М.: Издание Государственной Думы, 2017. - 80 с.

8. Федеральный закон «О стратегическом планировании в Российской Федерации» от 28.06.2014 № $172-$ Ф3 (с изм. на 18 июля 2019 г.) [Электронный ресурс]. - URL: http://docs.cntd.ru/document/420204138 (дата обращения: 10.12.2020).

9. Чмышенко, Е.В. Технологии и инструменты маркетинга в стратегическом региональном планировании: монография / Е. В. Чмышенко, С. В. Панкова, Е. Г. Чмышенко.-Оренбург: ОГУ, 2013. - 181 с.

10. Швецов, А.Н.Деструктивные стереотипы российского стратегического планирования и их возможные последствия для практики регионального стратегирования /А.Н Швецов, А.Н.Демьяненко, В.Н. Украинский // Регионалистика. - 2016. - т.3, № 3- С.48-60. 